\title{
Factors affecting survival in Gastric Adenocarcinoma at a Non-Cancer Center - A 20-year retrospective review
}

\author{
Sandeep A. Sathyanarayana ${ }^{1 *}$, Shailesh G2, Gary B. Deutsch ${ }^{2}$, Meredith A ${ }^{3}$, Louis J. Auguste ${ }^{2}$ \\ ${ }^{1}$ Department of Surgery, Meharry Medical College, Nashville, TN \\ ${ }^{2}$ Department of Surgery, Hofstra-NSLIJ School of Medicine, New Hyde Park, NY \\ ${ }^{3}$ Department of Biostatistics, Feinstein Institute of Medical Research, North Shore University Hospital System, Manhasset, NY.
}

Received: August 02, 2015; Accepted: October 18, 2015; Published: November 19, 2015

*Corresponding author: Sandeep A. Sathyanarayana, Department of Surgery, Surgical Oncology, Meharry Medical College, Nashville, 37208, TN

\begin{abstract}
Introduction: Although the incidence of gastric cancer has decreased over the last several decades, it continues to be the second most common cause of cancer death world-wide. While much of the current literature focuses on adjuvant and neo-adjuvant treatment of gastric cancer, there remains a relative paucity of longitudinal studies across low volume non-cancer hospitals. In this retrospective study, we set out to review our institutional data from the last two decades to look for any improvement in the outcomes of gastric cancerpatients and the factors responsible.
\end{abstract}

Methods: Data was collected from a tertiarycare hospital tumor registry and a total of 297 patients with gastric cancer were analyzed. Based on the date of surgery, these 297 patients were divided into Group 1(1990-2000)with 169 patients and Group 2 (2001-2010)with 128 patients.The Kaplan-Meier method was used for survival analysis and the curveswere compared using the log-rank test.

Results: Incomparing data between the two decades, average number of nodes dissected was 10 in group I while it was 15 in group II. The main difference between both groups,however,was an improved 5 -year survival of $47 \%$ in Group II vs. $29 \%$ in Group I. Also significant was the fact that $49 \%$ of patients had stage $3+$ disease at diagnosis in Group 1, compared to $30.4 \%$ in Group 2 ( $p<0.001 / 0.0089$ ).No microscopic evidence of tumor at the margins of resection was found in $82 \%$ of patients in both groups. Although there was no statistical significance, there was a trend towards increased use of adjuvant chemo-radiation in Group II.

Conclusion: Our study demonstratesan improvement in survival over the last decade in patients with gastric cancer.This trend seems to be as a result of early diagnosis of gastric cancer, negative resection margins and more radicalnodal dissection.

\section{Introduction}

Gastric cancer is a common neoplasm internationally and is an important cause of cancer-related death throughout the developing world. Efforts to improve survival are currently focused on multidisciplinary management including surgical resection, neoadjuvant and adjuvant chemioradiation $[1,2]$. To date, surgery remains the most effective therapy in the management of patients with resectable disease, though there still remains some controversy as to the extent of lymph node dissection required. Surgeons in Asian countries routinely perform extensive lymph node dissection compared to the West. Increasingly, there is a push towards aggressive nodal dissection in potentially curative gastric cancer $[3,4]$. Although the extent of lymph node dissection in gastric cancer still remains one of the most debated topics complete resection ensuring negative margins with adjacent lymphadenectomy is still regarded as the most optimal surgical technique leading to better 5-year survival. Most of the evidence regarding survival trends in gastric cancer comes from high volume centers. There is a relative paucity of studies focusing on outcomes of gastric cancer surgery at noncancer specialty centers despite the fact that a large proportion of these cases are treated at these institutions in the United States. To gain further insight into the survival trends of gastric cancer patients at a non-cancer specialty hospital, we conducted a comprehensive review of patients undergoing gastrectomy over the last two decades and evaluated trends and relevant factors affecting the 5-year overall survival.

\section{Methods}

This study was carried out at a tertiary non-cancer hospital after being approved by the institutional review board. Data was collected from the hospital's tumor registry and all patients who had gastrectomy from January 1, 1990 to December 30, 2010,were analyzed.

\section{Inclusion Criteria}

1.Any patient above 18 years of age who had any type of gastrectomy, total or partial, proximal or distal for stomach cancer.

2.Histological type: Patients with gastric adenocarcinoma, acinar cell carcinoma, carcinoid with adenocarcinoma, small cell carcinoma, large cell carcinoma, tumor cells of uncertain origin, and squamous cell carcinoma.

\section{Exclusion criteria}

1.Patients with histology showing only carcinoid disease, ulcer disease, or GIST.

2.Gastroesophageal junction tumors. 
A total of 297 patients were included in the final analysis of our study. Based on the date of surgery, these patients were then divided in to two groups: Group I ( $\mathrm{n}=169)$, including patients who had surgery between January 1, 1990 to December 31, 2000, and Group 2 ( $\mathrm{n}=128)$, including patients who had surgery between January 1, 2001 to December 31, 2010.

\section{Data collected}

Patient demographic variables such as age, gender, race, tobacco and alcohol history, along with type of gastrectomy, tumor histology, tumor characteristics (TNM $6^{\text {th }}$ edition staging), margin status, depth of invasion, number of nodes dissected, number of positive nodes, postoperative adjuvant chemo radiation were collected. Follow-up data was also collected based on the last visit to the oncologist and mortality data was derived from the hospital's tumor registry.

\section{Statistical Methods}

The chi-square test or Fisher's exact test, as deemed appropriate, was used to compare the two groups (Group I: 1990-2000 vs. Group II: 2001-2010) for categorical data [i.e. gender, race, smoking and alcohol history, pathological type, surgery type, resection type, other organ resection, lymph node status (N0, N1, N2 or N3), tumor invasion (T1, T2, T3, T4), distant metastasis (M0 or M1), pathological stage (IA, IB, II, IIIA, IIIB, or IV), chemotherapy, radiation therapy] and the Mann-Whitney test was used to compare the two groups for continuous data (i.e. nodes examined, nodes positive) and was reported as mean \pm standard deviation and median.

Standard methods of survival analysis were applied to the data, i.e., computing the Kaplan-Meier [6] product limit curves, where different stratification groups were used in each analysis. In cases where the subject was alive or lost to follow-up, the number of months until last follow-up was used and considered censored. Groups were compared using the log-rank test. Median survival rates for each group were obtained from the KaplanMeier/Product-Limit Estimates and their corresponding 95\% confidence intervals were computed, using Greenwood's formula [7] to calculate the standard error.

A separate multivariate Cox proportional hazards model was developed for Group I (1990-2000) and Group II (20012010) using backwards selection to evaluate the independent influences of prognostic factors on survival. Hazard ratios (HRs) and associated 95\% confidence intervals were calculated. The variables included in the selection process were: age, sex, race, smoking history, alcohol history, pathological stage, number of nodes examined, margins, depth of invasion, and type of gastrectomy. It was determined that pathological stage was a linear combination of tumor invasion (T), node status $(\mathrm{N})$, and distant metastasis (M), and therefore, these variables were not included in the selection process. The proportional hazards assumption was assessed and martingale residual plots analysis was applied to check the functional form of continuous variables. A result was considered statistically significant at the $\mathrm{p}<0.05$ level of significance. All analyses were performed using SAS version 9.3 (SAS Institute Inc., Cary, NC).

\section{Findings}

A total of 297patients were included in the study: Group I with169 patients and Group II with 128 patients. Follow-up data for patients was available until March 2011. Group I had 147 (86.98\%) deaths of 169 patients while group II had 58 deaths of $128(45.31 \%)$ patients from all causes at the end of study period.

Detailed information on patient demographicsis listed in Table 1. As shown in the table, there were no differences with respect to gender between the two groups. Race was a statistically significant factor between the two groups with patients in Group I predominantly whites and had higher prevalence of smoking while group II had more non-white patients (included African Americans, Hispanics, Asians and others), with more prevalent history of alcohol use.

The two groups were also analyzed based on the type of gastrectomy, TNM staging, depth of invasion, margin status and the number of nodes examined. Table 2 depicts the staging based on AJCC $6^{\text {th }}$ edition. Based on the above data, the T status was statistically significant across both groups. T3 tumors were predominant in Group I(45.2\% vs $24.2 \%$ ) while group II predominantly had $\mathrm{T} 2$ disease $(26.8 \%$ vs $38.3 \%$; $\mathrm{p}=0.0033)$. Similarly, group I had more patients with stage $3 \mathrm{~A}$ cancer $(28.6 \%$ vs $11.2 \%$ )while group II had more patients with stage 2 cancer $(21.7 \%$ vs $25.6 \%)$ and this difference was statistically significant across the groups $(\mathrm{p}=0.0157)$.

More patients in group II underwent partial / subtotal gastrectomy compared to group I (60\% vs $33.7 \%$ ), while the number of total / radical gastrectomy remained the same. Although, this was statistically significant (p 0.0001), 47.9\% patients in group I and $21 \%$ of group II patients underwent undefined extent of gastrectomy that could not be delineated from the data available. Considering overall stages, $49 \%$ of patients had Stage 3+ disease at diagnosis in Group 1, compared to $30.4 \%$ in Group 2 ( $\mathrm{p}<0.001 / 0.0089)$. An R0 resection (no microscopic evidence of tumor) was achieved in $82 \%$ of patients across the groups.

\section{Survival data}

As depicted in the Figure 1, group II had an improved overall 5 -yearsurvival compared to group $1(47 \%$ vs. $29 \%$; $p=0.0026)$. While R0 resection was a significant predictor of improved survival across the groups, only patients in Group II obtained a statistically significant benefit Figure 2. On multivariable analysis, positive margin status proved to be an independent risk factor of survival for Group I (HR 2.65; 95\%CI 1.56-4.5; $\mathrm{p}<0.0001$ ) and Group II (HR 2.68; 95\%CI 1.36- 5.27; p = 0.004)

\section{Lymph node data}

An aggressive lymph node dissection was evident in Group II compared to Group I.An average of 10 nodes were dissected in group I compared to 15 nodes dissected in group II, which 
Factors affecting survival in Gastric Adenocarcinoma at a Non-Cancer Center - A 20 -

Table 1: Patient characteristics enrolled in the study.

\begin{tabular}{|c|c|c|c|c|c|}
\hline & \multicolumn{2}{|c|}{$1990-2000$} & \multicolumn{2}{|c|}{$2001-2010$} & \multirow[b]{2}{*}{ p-value } \\
\hline & $\mathrm{N}$ & $\%$ & $\mathrm{~N}$ & $\%$ & \\
\hline \multicolumn{6}{|l|}{ Sex } \\
\hline Male & 111 & 65.68 & 84 & 65.63 & \multirow{2}{*}{0.9920} \\
\hline Female & 58 & 34.31 & 44 & 34.38 & \\
\hline \multicolumn{6}{|l|}{ Race } \\
\hline Whites & 141 & 83.43 & 84 & 65.63 & \multirow{2}{*}{0.0004} \\
\hline Non-whites & 28 & 16.57 & 44 & 34.38 & \\
\hline \multicolumn{6}{|l|}{ Tobacco history } \\
\hline Yes & 135 & 80.36 & 80 & 62.50 & \multirow{2}{*}{0.0006} \\
\hline No & 33 & 19.64 & 48 & 37.50 & \\
\hline \multicolumn{6}{|l|}{ Alcohol history } \\
\hline Yes & 54 & 32.14 & 60 & 46.88 & \multirow{2}{*}{0.0099} \\
\hline No & 114 & 67.86 & 68 & 53.13 & \\
\hline
\end{tabular}

Table 2: Type of gastrectomy and tumor characteristics across Group I \& Group II.

\begin{tabular}{|c|c|c|c|c|c|}
\hline & \multicolumn{2}{|c|}{$1990-2000$} & \multicolumn{2}{|c|}{ 2001-2010 } & \multirow[b]{2}{*}{ p-value** } \\
\hline & $\mathbf{N}$ & $\%$ & $\mathbf{N}$ & $\%$ & \\
\hline \multicolumn{6}{|l|}{$\mathrm{T}$} \\
\hline Tis & 5 & 2.98 & 9 & 7.03 & \multirow{5}{*}{0.0033} \\
\hline $\mathrm{T} 1$ & 28 & 16.67 & 29 & 22.66 & \\
\hline $\mathrm{T} 2$ & 45 & 26.79 & 49 & 38.28 & \\
\hline $\mathrm{T} 3$ & 76 & 45.24 & 31 & 24.22 & \\
\hline $\mathrm{T} 4$ & 14 & 8.33 & 10 & 7.81 & \\
\hline \multicolumn{6}{|l|}{$\mathrm{N}$} \\
\hline No & 64 & 39.75 & 59 & 47.20 & \multirow{4}{*}{0.0964} \\
\hline $\mathrm{N} 1$ & 67 & 41.61 & 41 & 32.80 & \\
\hline $\mathrm{N} 2$ & 26 & 16.15 & 16 & 12.80 & \\
\hline N3 & 4 & 2.48 & 9 & 7.20 & \\
\hline \multicolumn{6}{|l|}{ M } \\
\hline M0 & 149 & 90.85 & 115 & 94.26 & \multirow{2}{*}{0.2847} \\
\hline M1 & 15 & 9.15 & 7 & 5.74 & \\
\hline \multicolumn{6}{|l|}{ Stage } \\
\hline 0 & 5 & 3.11 & 9 & 7.20 & \multirow{7}{*}{0.0157} \\
\hline $1 \mathrm{~A}$ & 21 & 13.04 & 23 & 18.40 & \\
\hline $1 \mathrm{~B}$ & 21 & 13.04 & 23 & 18.40 & \\
\hline 2 & 35 & 21.74 & 32 & 25.60 & \\
\hline $3 \mathrm{~A}$ & 46 & 28.57 & 14 & 11.20 & \\
\hline $3 \mathrm{~B}$ & 14 & 8.70 & 10 & 8.00 & \\
\hline 4 & 19 & 11.80 & 14 & 11.20 & \\
\hline Depth o & & & & & \\
\hline
\end{tabular}

Citation: Sathyanarayana SA, Shailesh G, Deutsch GB, Meredith A, Auguste LJ (2015) Factors affecting survival in Gastric 


\begin{tabular}{|c|c|c|c|c|c|}
\hline Mucosa & 13 & 7.74 & 28 & 22.05 & \multirow{7}{*}{$<0.0001$} \\
\hline Submucosa & 3 & 1.79 & 12 & 9.45 & \\
\hline Musc. Propria & 30 & 17.86 & 45 & 35.43 & \\
\hline Serosa & 8 & 4.76 & 19 & 14.96 & \\
\hline Adjacent organs & 11 & 6.55 & 19 & 14.96 & \\
\hline Metastasis & 3 & 1.79 & 4 & 3.15 & \\
\hline Unknown & 100 & 59.52 & 0 & 0.00 & \\
\hline \multicolumn{6}{|l|}{ Margins } \\
\hline No residual tumor & 140 & 82.84 & 105 & 82.68 & \multirow{4}{*}{0.0835} \\
\hline Microscopic tumor & 12 & 7.10 & 17 & 13.39 & \\
\hline Macroscopic tumor & 6 & 3.55 & 1 & 0.79 & \\
\hline Unknown & 11 & 6.51 & 4 & 3.15 & \\
\hline Nodes positive & \multicolumn{2}{|c|}{$\begin{array}{l}3.77 \pm 6.33 \\
(\text { median }=1)\end{array}$} & \multicolumn{2}{|c|}{$\begin{array}{l}3.58 \pm 5.62 \\
(m e d i a n=1)\end{array}$} & 0.6096 \\
\hline \multicolumn{6}{|l|}{ Type of Gastrectomy } \\
\hline Partial / Subtotal gastrectomy & 57 & 33.7 & 77 & 60.1 & \multirow{3}{*}{0.0001} \\
\hline Total / Radical Gastrectomy & 31 & 18.3 & 24 & 18.7 & \\
\hline Gastrectomy, NOS & 81 & 47.9 & 27 & 21.0 & \\
\hline
\end{tabular}

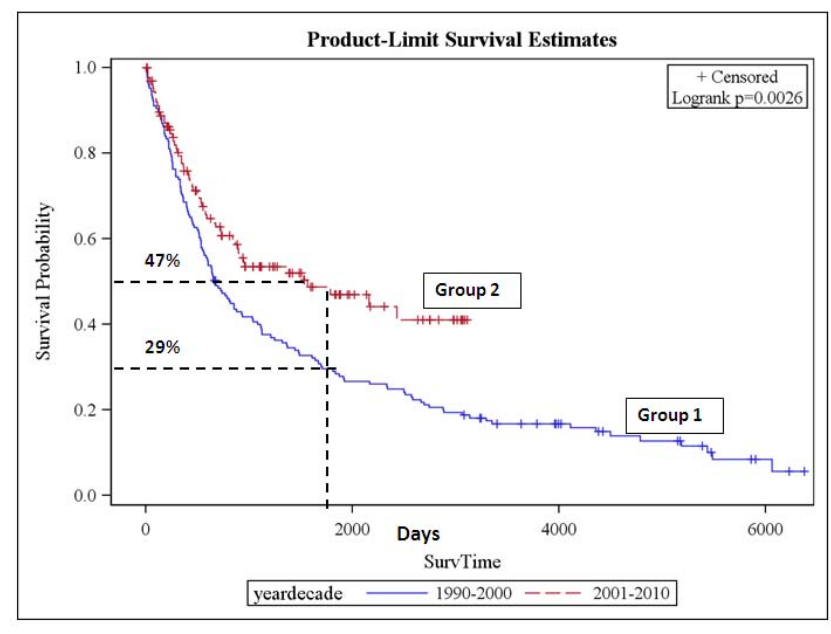

Figure 1: Overall Survival.

was statistically significant $(\mathrm{p}<0.0001)$. However there was no statistical significance with regard to the number of patients with positive lymph nodes across two groups. Considering 15 nodes as a minimum requirement for adequate lymphadenectomy and staging, we plotted Kaplan-Meier survival curves and found that patients with more than 15 nodes dissected in the surgical specimen had a trend towards improved survival. Multivariable analysis predicted an improved survival in patients with more than 15 nodes dissected in the surgical specimen in Group II patients (HR 2.92; 95\%CI 1.54-5.54; p=0.001). With 15 nodes as a cutoff point for adequate lymphadenectomy, we compared patients from both groups to assess survival on Kaplan Meier plots and demonstrated patients from Group II demonstrated statistically significant survival benefit $(p=0.05)$. Figure 3

\section{Chemoradiation data}

4.In group I, $16.5 \%$ patients $(n=28)$ received adjuvant chemotherapy and $6 \%$ patients $(n=13)$ received adjuvant radiotherapy compared to group II where $28.9 \%$ patients $(n=37)$ received adjuvant chemotherapy and $25.8 \%$ patients $(n=33)$ received radiotherapy. On further analysis, adjuvant chemo radiation failed to demonstrate survival benefit in both the groups.

\section{Discussion}

Management of gastric cancer requires a multimodality approach and surgery remains the mainstay of treatment. Reviewing the SEER database, the 5-year overall survival of gastric cancer patients was $21 \%$ in 1990 that increased to $28.2 \%$ in 2008. Our study findings demonstrate a 5-year overall survival rate of $29 \%$ from 1990 to 2000 compared to $47 \%$ from 2000 to 2010.

This trend could have resulted from two factors as depicted from our results:

1.Diagnosis of gastric cancer at an earlier stage as evidenced by increasing number of patients diagnosed with earlier stage disease in group II.

2.More aggressive nodal dissection with an average of 15 nodes in group II as opposed to 10 nodes in group I.

Though our study demonstrated improved survival 


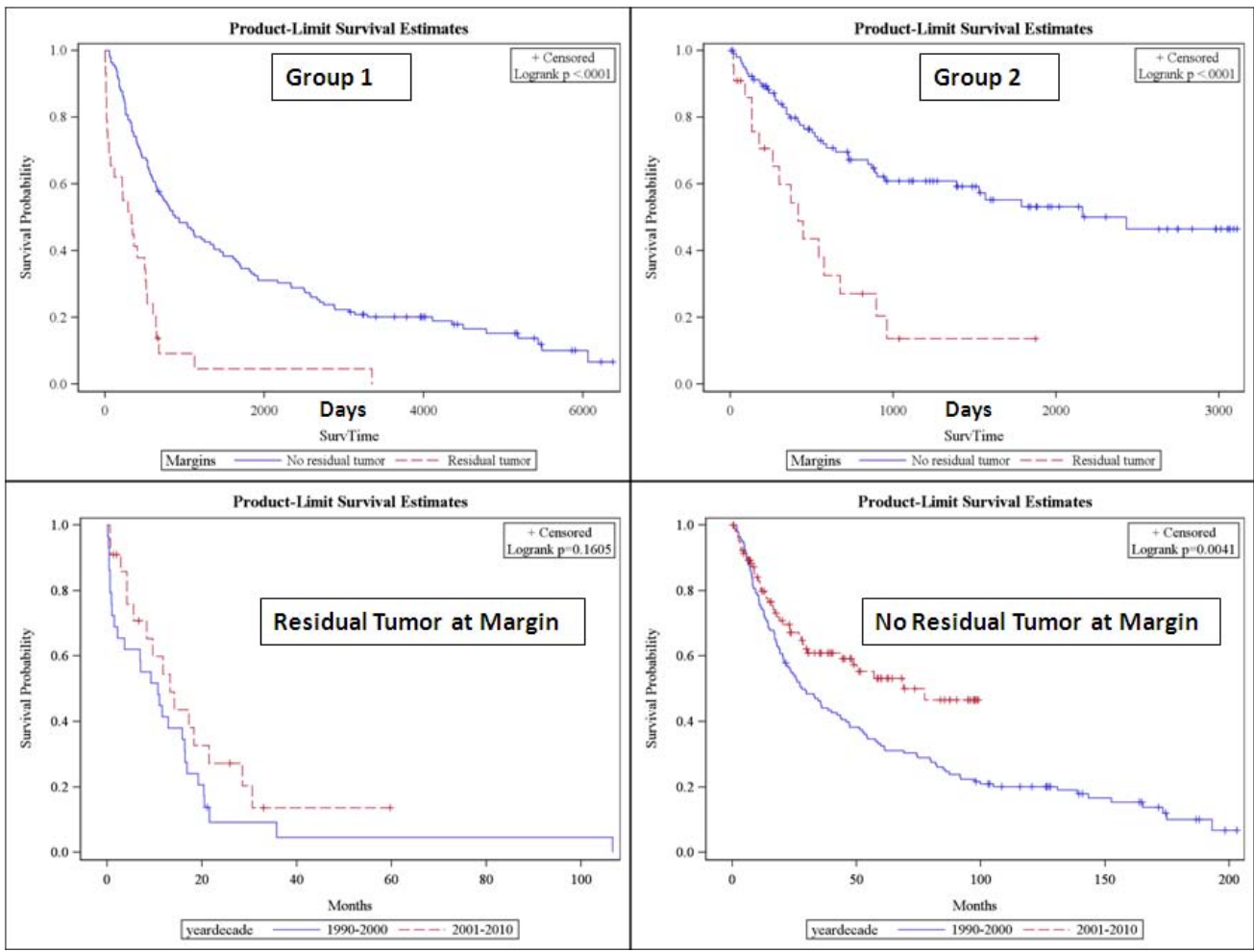

Figure 2: Residual tumor at margin.
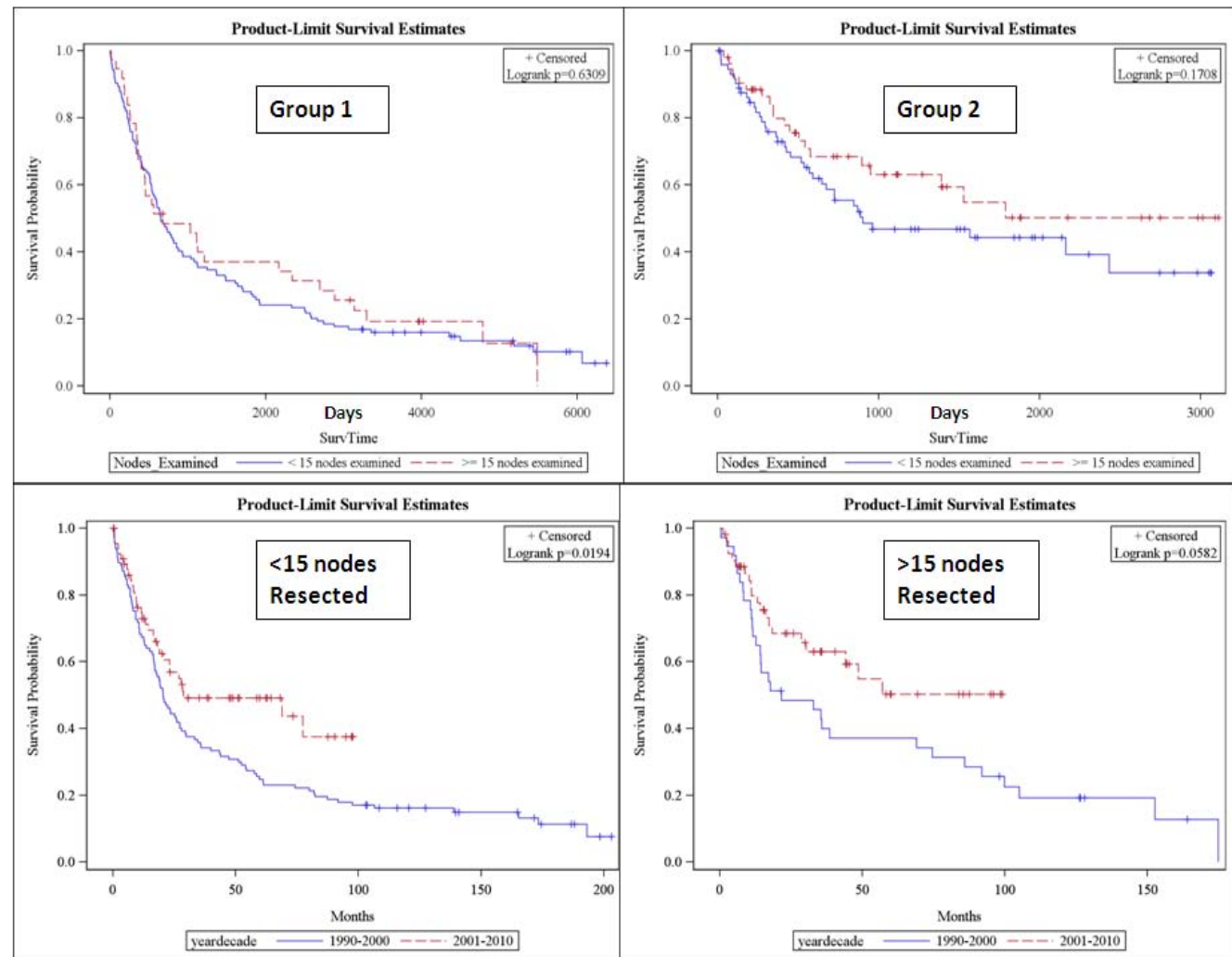

Figure 3: Nodes.

Citation: Sathyanarayana SA, Shailesh G, Deutsch GB, Meredith A, Auguste LJ (2015) Factors affecting survival in Gastric Adenocarcinoma at a Non-Cancer Center - A 20-year retrospective review. Gastroenterol Pancreatol Liver Disord 2(3): 1-7. 

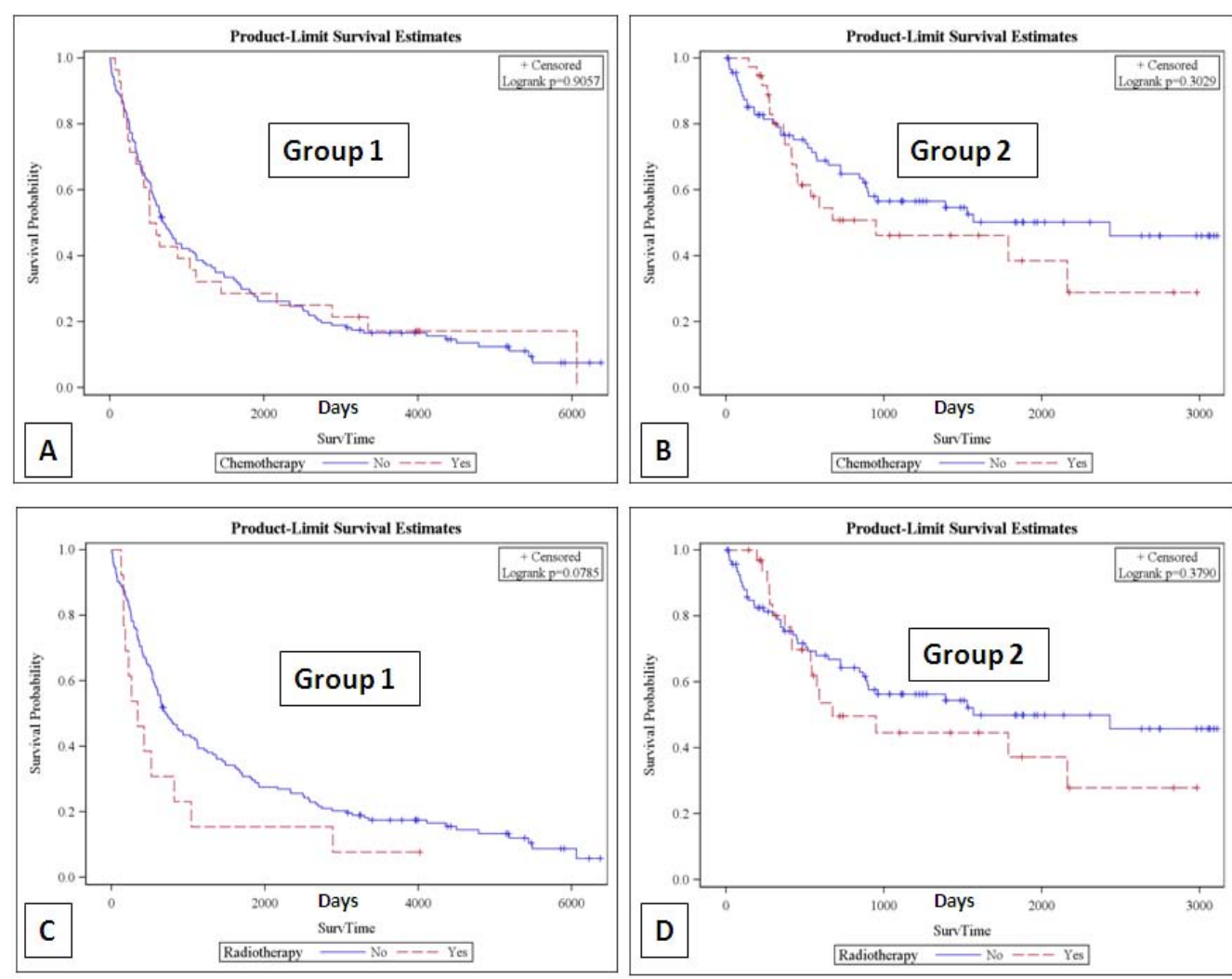

Figure 4: Chemoradiation.

associated with an increased number of nodes dissected, the R0 resection (82\%) status across the two decades was similar. Adjuvant chemoradiotherapy is a proven treatment modality to improve survival in resected gastric patients [10, 11], even with positive microscopic margins [12]. Our study findings did not find adjuvant chemoradiation therapy to be a significant factor to affect overall survival across the two decades. This finding is contrary to recent evidence in the literature and may have resulted from the fact that less than a third of our patients received chemoradiation therapy.

The concept of a more thorough nodal dissection became more accepted in the latter part of the 1990s to early 2000s, thus we divided our study population into 2 groups. Despite the conflicting evidence regarding the extent of nodal dissection, a recent SEER database review demonstrated a linear improvement in 5-year survival in patients with increasing number of lymph nodes resected [13]. On the other hand, several prospective randomized controlled trials and met-analyses failed to demonstrate a clear survival benefit with D2 vs D1 lymphadenectomy [14-16]. Although the benefit between a D1 or D2 lymphadenectomy are unclear, some studies suggest less than one third of patients undergo an adequate lymphadenectomy ( $>15$ nodes) stressing the importance of the extent of lymphadenectomy for gastric cancer [17-19]. We therefore, postulate that the trend towards an increased 5-year survival results from aggressive nodal dissection and an earlier diagnosis.

\section{Conclusion}

Our study does demonstrate an improvement in overall survival over the last decade in patients with gastric cancer at a low volume non-cancer center. This trend may be a result of early diagnosis of gastric cancer, good R0 resection and more radical nodal dissection.

\section{References}

1. Macdonald JS, Smalley SR, Benedetti J, Hundahl SA, Estes NC, Stemmermann GN, et al. Chemoradiotherapy after surgery compared with surgery alone for adenocarcinoma of the stomach or gastroesophageal junction. N Engl J Med. 2001;345(10):725-730.

2. Cunningham D, Allum WH, Stenning SP, Thompson JN, Van de Velde CJ, Nicolson $\mathrm{M}$, et al. Perioperative chemotherapy versus surgery alone for resectablegastroesophageal cancer. N Engl J Med. 2006;355(1):1120.

3. Noguchi Y, Yoshikawa T, Tsuburaya A, Motohashi H, Karpeh MS, Brennan MF, et al. Is gastric carcinoma different between Japan and the United States? Cancer. 2000;89(11):2237-2246.

4. Songun I, Putter H, Kranenbarg EM, Sasako M, van de Velde CJ, et al. Surgical treatment of gastric cancer: 15-year follow-up results of the randomised nationwide Dutch D1D2 trial. Lancet Oncol. 2010;11(5):439-449.

5. Siegel R, Naishadham D, Jemal A. Cancer statistics. 2012. CA Cancer J Clin. 2012;62(1):10-29. doi: 10.3322/caac.20138.

6. Lee E. T. Statistical Methods for Survival Data Analysis. 2nd ed. New 
York: John Wiley \& Sons; 1992.

7. Greenwood M. The Errors of Sampling of the Survivorship Table. Vol 33 of Reports on Public Health and Medical Subjects. London: Her Majesty's Stationery Office. 1926.

8. Bonenkamp JJ, Hermans J, Sasako M, van de Velde CJ, Welvaart K, Songun I, et al. Dutch Gastric Cancer Group; Extended lymph-node dissection for gastric cancer. N Engl J Med. 1999;340(12):908-914.

9. Cuschieri A, Fayers P, Fielding J, Craven J, Bancewicz J, Joypaul V, et al. Postoperative morbidity and mortality after D1 and D2 resections for gastric cancer: preliminary results of the MRC randomised controlled surgical trial. The Surgical Cooperative Group. Lancet . 1996;347:995

10. Dai Q1, Jiang L, Lin RJ, Wei KK, Gan LL, Deng CH, et al. Adjuvant chemoradiotherapy versus chemotherapy for gastric cancer: A meta-analysis of randomized controlled trials. J Surg Oncol 2015;111(3):277-284. doi: 10.1002/jso.23795.

11. Seyedin S, Wang PC, Zhang Q, Lee P. Benefit of Adjuvant Chemoradiotherapy for Gastric Adenocarcinoma: A SEER Population Analysis. Gastrointest Cancer Res. 2014;7(3-4):82-90.

12. Stiekema J, Trip AK, Jansen EP, Aarts MJ, Boot H, Cats A, et al. Does Adjuvant Chemoradiotherapy Improve the Prognosis of Gastric Cancer After an R1 Resection? Results from a Dutch Cohort Study. Ann Surg Oncol. 2014;22(2):581-588. doi: 10.1245/s10434-014-4032-8.
13. Smith DD, Schwarz RR, Schwarz RE. Impact of total lymph node count on staging and survival after gastrectomy for gastric cancer: data from a large US-population database. J Clin Oncol. 2005;23:7114-7124.

14. Jiang L, Yang KH, Guan QL, Zhao P, Chen Y, Tian JH, et al. Survival and recurrence free benefits with different lymphadenectomy for resectable gastric cancer: a meta-analysis. J Surg Oncol. 2013;107(8):807-814. doi: 10.1002/jso.23325.

15. Dent DM, Madden MV, Price SK. Randomized comparison of R1 and R2 gastrectomy for gastric carcinoma. Br J Surg. 1988;75(2):110-112.

16. Degiuli M, Sasako M, Ponti A, Vendrame A, Tomatis M, Mazza C, et al. Randomized clinical trial comparing survival after D1 or D2 gastrectomy for gastric cancer.Br J Surg. 2014;101(2):23-31. doi: 10.1002 /bjs. 9345 .

17. Coburn NG, Swallow C, Quan ML, Law C. Significant regional variation in treatment and survival of gastric cancer. J Clin Oncol. 2005;23:309s.

18. Baxter NN, Tuttle TM. Inadequacy of lymph node staging in gastric cancer patients: a population-based study. Ann Surg Oncol. 2005;12:981-917.

19. Bilimoria KY, Talamonti MS, Wayne JD, Tomlinson JS, Stewart AK, Winchester DP, et al. Effect of hospital type and volume on lymph node evaluation for gastric and pancreatic cancer. Arch Surg. 2008;143(7):671-688 . doi: 10.1001/archsurg.143.7.671. 